\title{
Development, Implementation (Pilot) and Evaluation of a Demand-Responsive Transport System
}

\author{
Mascha Brost ${ }^{1, *}$, Matthias Klötzke ${ }^{1}$, Gerhard Kopp ${ }^{1}$, Oliver Deißer ${ }^{1}$, Eva-Maria Fraedrich ${ }^{2}$, \\ Katharina Karnahl ${ }^{3}$, Tim Sippel ${ }^{4}$, Alexander Müller ${ }^{5}$ (i) and Stefanie Beyer ${ }^{5}$ \\ 1 German Aerospace Center, Institute of Vehicle Concepts, Pfaffenwaldring 38-40, 70569 Stuttgart, Germany; \\ Matthias.Kloetzke@dlr.de (M.K.); Gerhard.Kopp@dlr.de (G.K.); Oliver.Deisser@dlr.de (O.D.) \\ 2 German Aerospace Center, Institute of Transport Research, Rutherfordstraße 2, 12489 Berlin, Germany; \\ eva.fraedrich@gmail.com \\ 3 German Aerospace Center, Institute of Transportation Systems, Lilienthalplatz 7, 38108 Braunschweig, \\ Germany; Katharina.Karnahl@dlr.de \\ 4 ZIRIUS, University of Stuttgart, Seidenstr. 36, 70174 Stuttgart, Germany; tim.sippel@zirius.uni-stuttgart.de \\ 5 Hochschule Esslingen, Faculty of Automotive Engineering, University of Applied Sciences, Kanalstraße 33, \\ 73728 Esslingen, Germany; Alexander.Mueller@hs-esslingen.de (A.M.); stefanie.beyer@hs-esslingen.de (S.B.) \\ * Correspondence: Mascha.Brost@dlr.de
}

Received: 9 May 2018; Accepted: 22 May 2018; Published: 30 May 2018

\begin{abstract}
This paper presents the partial results of the first phases of the BOOLEAN (Bürgerorientierte Optimierung der Leistungsfähigkeit, Effizienz und Attraktivität im Nahverkehr) research project. The demand-responsive transport and operating systems as well as virtual vehicle concepts are developed in a "real-world laboratory" in Schorndorf. The demand-responsive transport system is implemented as a part of the existing public transport system and will be tested for nine months. The paper focuses on the derivation of system requirements for the operating system and vehicle concepts. The virtual vehicle concepts developed within the project are specifically designed according to the needs of demand-responsive transport systems and are based on automation technologies and electric propulsion. An inter- and transdisciplinary approach integrates perspectives from the social, technical and computer sciences and various local stakeholders (operators, municipality, politics and citizens of a medium sized town in Southern Germany). Transformative processes are induced, supported and scrutinized during and beyond the pilot phase.
\end{abstract}

Keywords: demand-responsive transport; real-world laboratory; trans- and interdisciplinary research; autonomous driving; barrier-free vehicle concepts

\section{Introduction}

Transport systems in urban areas are facing increasing challenges regarding congestion, air quality, greenhouse gas emission, noise emission and individual motorized traffic's enduring persistence. Public transport should be further improved in order to meet these challenges. While the development of demand-responsive transport (DRT) systems has often focused on areas with very high population densities (i.e., inner city centers [1]) or rural areas [2,3], it often neglects medium and small municipalities and their specific challenges regarding fluctuating passenger numbers and commuter traffic to urban centers. Even where DRT systems were introduced, beginning in the 1970s, they often failed for several reasons and were withdrawn [4]. Rural-urban commuter traffic today is mainly conducted by private motorized vehicles [5,6], whereas public transport means are less-used and often perceived as inflexible. The possibilities for improving conventional public transport by increased temporal and spatial availability are limited by economic and ecological constraints resulting from low occupancy factors. Occupancy tends to be low in sparsely populated areas, especially in off-peak 
periods. The frequency of public transport is usually accordingly low, being adapted to passenger numbers, which can highly fluctuate throughout the day. For some areas, passenger demand per route is generally low throughout the operating time. The definition of operating period, scheduling intervals and routing is a compromise between customer convenience on the one hand and economical and ecological requirements on the other hand. In addition to the described conflict of objectives, requests from passengers oppose those of local residents, as increased service frequency results in higher emission of noise and pollutants.

To address these conflicting requirements, new DRT concepts as well as innovative vehicle concepts must be considered. In particular, with new, demand-oriented vehicle concepts and the application of digital solutions, the requirements in terms of time, comfort, safety and environmental conditions can be addressed. Increased availability of public transport might induce a self-energizing effect by enhancing attractiveness and passenger numbers, which results in the possibility of further increasing availability. In contrast to many recently implemented systems (e.g., [1,7]), the DRT presented in this paper is integrated into existing public transport within and adjacent to the operation area (price system and connection information).

The paper is structured into a section addressing the operation system and a second section presenting details about the vehicle concept. Both sections show how inter- and transdisciplinary participative development processes contribute to the derivation of technical parameters of the respective concept.

\section{Development of the Demand-Responsive Transport System}

We present the development of a DRT system operating without fixed routes, timetables and stations. The project scope comprises the evaluation of local conditions and user requirements, the development of an operating system including a smart phone application and a telephone order system, the implementation and operation of the transport system in the municipality of Schorndorf for nine months, the evaluation of the pilot operation and the derivation of task-specific vehicle concepts, shown in Figure 1.

\begin{tabular}{|l|l|l|l|}
\hline & Participation & Operation Concept & Vehicle Concept \\
\hline 1 & Initial position & Specification analysis & Specification management \\
\hline 2 & User perspective & Architecture & Drafts/Sketches \\
\hline 3 & Expert perspective & Implementation & Concepts \\
\hline 4 & Monitoring pilot phase & Testing/pilot phase & Construction \\
\hline 5 & Public dialogue & Evaluation & Installation of demonstrator \\
\hline & & Knowledge Management & \\
\hline
\end{tabular}

Figure 1. Project structure.

Differing from existing similar approaches for DRT systems, the system developed for Schorndorf will replace parts of the existing public transport at certain operating times. This implies fundamental impacts on the complete system specification, as a heterogeneous user group must be considered with special attention to elderly and mobility restrained persons. The innovative DRT concept must not exclude any part of the population. Effects concern parameters for operation (e.g., operation area and time span), user interaction and information (e.g., integration of a telephone service supplementing a 
smart phone application) and vehicle concept (special focus on barrier-free accessibility). The system will be integrated into the pricing system of Stuttgart's Transport and Tariff Authority (VVS), meaning that conventional tickets (e.g., commutation tickets) can be used without additional charge.

The DRT system is developed in the format of a real-world laboratory. Real-world laboratories address existing problems connected to transformation processes by an inter- and transdisciplinary approach that involves permanent interaction of the engaged expert groups (scientific disciplines and practical actors), dissolving borders between specialist fields, integrating knowledge, methods and mindsets to a common understanding [8-10].

This paper focuses on specification of system requirements and the development of vehicle concepts tailored towards future DRT systems.

\subsection{Specification of System Requirements}

System requirements are derived in an inter- and transdisciplinary process that integrates expert knowledge from scientists of the social sciences as well as the technical and computer sciences, various local stakeholders comprising a municipality, a transportation company, a bus operating company, the local citizenship and a vehicle manufacturer. Specifically, the project consortium consists of the German Aerospace Center (DLR), the Hochschule Esslingen University of Applied Sciences, the University of Stuttgart, Stuttgart's Transport and Tariff Authority (VVS), Knauss Linienbusse, and the City of Schorndorf. Citizens of Schorndorf act as co-designers in the development process in several workshops and provide input for the requirement assessment within a structured citizen participation concept that accompanies the complete development process. Citizen participation includes inter alia public information events, weekly citizens' consultation by the municipality of Schorndorf and a project homepage. In order to methodologically include the heterogeneous requirements of local citizens, the approach of design thinking [11] was applied in several workshops. Four personas [12] developed within the workshops represent local target groups: senior citizens, mobility-restricted persons, persons regularly using buses, and persons regularly using cars. They allow the derivation of the requirements of passengers and local residents. The interaction of methods, also including requirements engineering [13], is described in detail in [14].

Besides the requirements gained in the citizen participation process, the interests of various stakeholders must be assessed. Conflicting goals are evaluated by the project consortium and adequately considered when determining system specifications (Figure 2). Legislative and regulatory approval aspects must be fulfilled and constitute additional requirements.

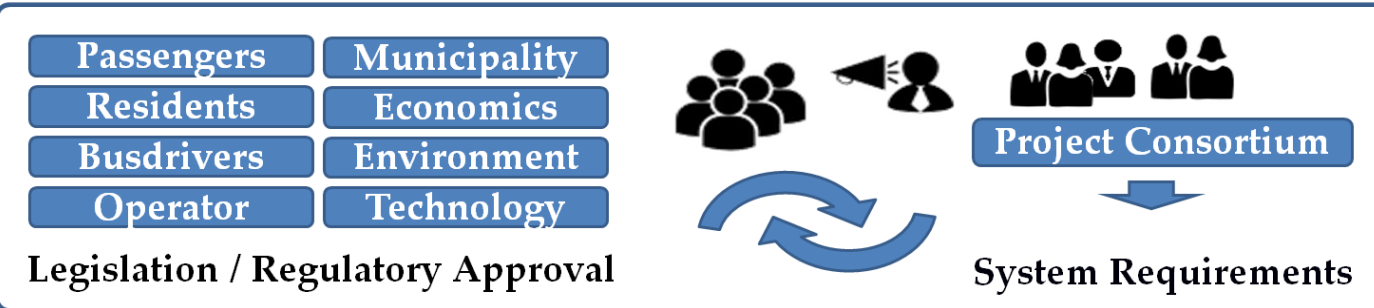

Figure 2. Derivation of system requirements under consideration of affected stakeholders' interests.

Differing from conventional participation processes, stakeholders' requirements are not collected simultaneously without referring to one another. Instead, discourse between the engaged expert groups is promoted, creating synergies by the interaction between science, economy, municipality, politics and society [15]. The final determination of the system requirements comprises the transfer into technical parameters and hence incorporates results of this cooperative development process.

In order to evaluate the service of public transport and support the decision process for systems parameters, quality criteria listed in the DIN EN 13816 (2002) are considered. The criteria which are taken as a basis are operational availability, accessibility, information, time, customer support, comfort, 
safety, and environmental conditions. These criteria are addressed by the complete system of operation, operability and the vehicle concept.

Besides the application of the described methods, the determination of system specification with the involvement of numerous stakeholders correlated to the characteristics of a real-world laboratory requires extensive communication. Information exchange within the interdisciplinary project consortium is supported by a "specification book". Due to the research character of the project, system requirements are not described in a tender specification and accordingly defined in a technical specification document as described in DIN 69 901-5. Instead, the development of system requirements and respective technical solutions is a dynamic process within the project and is continuously updated in a central document accessible to all project partners.

System requirements described in the specification book comprise spatial and temporal system boundaries, operation and operability parameters and vehicle requirements. In the following, we exemplarily describe the derivation of selected parameters.

\subsubsection{Determination of Operation Area and Period}

Schorndorf is a medium-sized major district town $26 \mathrm{~km}$ east of Stuttgart within the catchment area. It consists of the actual urban core of Schorndorf with 25,000 inhabitants and seven incorporated communities with a further 15,000 inhabitants. Schorndorf's structure is typical for Baden-Württemberg; hence, the results gained in the real-world laboratory can be applied to other communities. The population density of 681 inhabitants $/ \mathrm{km}^{2}$ is well above the average of 142 inhabitants $/ \mathrm{km}^{2}$ living in the on-demand operation areas with rural structures that were analyzed. Different to many of them, the presented system is not aimed at providing a basic, rudimentary public transport system, but to enhance the attractiveness of an existing, well-developed system.

In order to define an adequate operation area for the on-demand transport system, prevailing traffic conditions were examined. Analyses included spatial distribution of points of interest, road traffic situation (congestion), passenger car occupancy rate, commuter flows, existing public transport (e.g., frequency, route alignment, number of passengers and isochrones regarding accessibility of main station, Figure 3) and characteristics of transport user groups (public and individual transport). Research on legislative framework completed analysis of as-is state conditions.

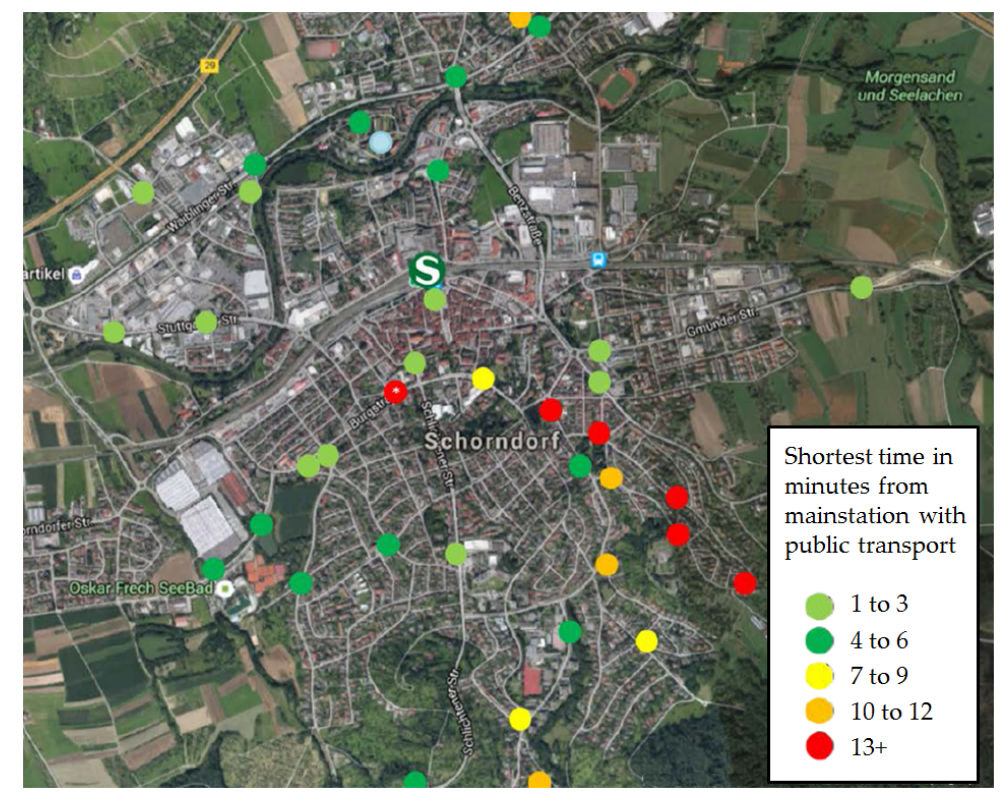

Figure 3. Reachability analysis—isochrone map showing travelling time from main station. 
Analysis of data served as preparation for a co-creation workshop applying the methodology of design thinking [11], where scientists, vehicle manufacturer employees and citizens developed system requirements together including parameters for operation area and span of service. Four target group-related personas were developed within the workshop. Requirements regarding span of service varied widely according to different user profiles of the four diverse personas.

Results of the co-creation workshop were evaluated by the consortium under close interaction of municipality, transportation authority, bus operator company and science. Conflicts of objectives were evaluated in continuous inter- and transdisciplinary dialogue. Limiting constraints such as the number of deployable busses (personnel availability and cost), operable area size, and integration of certain points of interests (hospital, graveyard, swimming pool) led to the decision of defining the southern part of the urban core of Schorndorf as the operating area. This area is also appropriate regarding existing public transport with two urban bus routes and four trans-regional bus corridors served in this area. The two urban bus routes will be replaced in the initial phase only after the Friday afternoon peak ( 3 p.m.) until Sunday midnight. This period might be extended in the course of the pilot phase. The trans-regional bus routes stay unaffected. Scientific aspects regarding the determination of this operation period induce a considerable impact on mobility behavior, while limiting irritations caused by the innovative mobility experiment by avoiding periods when travelling is particularly time-sensitive (peak hours). Replacement of bus routes is a particular objective for the real-world laboratory in order to create considerable impact with the innovative transport concept and evaluate the acceptance of a heterogeneous user group.

Part of the heterogeneous user group are elderly people without access to smartphones. Hence, the provision of a telephone service covering the complete span of service is mandatory in addition to input options via smartphone app or web interface. Financial expenses for telephone service constitute one boundary condition for the definition of the operating period.

\subsubsection{Definition of Pick-Up Areas/Stopping Points}

The application of discrete stopping points versus continuous pick-up areas was evaluated with consideration of legislative, route planning, operational, and customer convenience aspects. Advantages connected to discrete stopping points such as more efficient routes, simplified passenger identification, local stopping restrictions and dissociation from "Ruftaxi" (legislative aspect) predominate over the advantage of minimizing walking distances for passengers, and hence the system will operate with discrete stopping points. The targeted walking distance to stopping points is $150 \mathrm{~m}$ within the operation area. A maximum distance of $200 \mathrm{~m}$ should not be exceeded.

Digital maps were analyzed to evaluate local conditions (e.g., grass verges between road and footpath which prevent boarding and alighting, stopping restrictions). On-site visits complemented digital analyses for missing data or unclear situations [16]. Details such as road-wise accessibility with busses, as in Figure 4, were defined in close accordance with scientists, the municipality and bus operators and consideration of the citizen workshop results.

According to the flexible concept without fixed routes and no restriction to existing bus stations, additionally introduced stopping points (brown dots) will not be equipped with physical infrastructure. This imposes an obstacle for some mobility-restricted persons. During the pilot phase, affected persons must continue to use existing stopping points (yellow dots). For future regular DRT systems, where barrier-free public transport has to be provided from 2022 onwards according to the law PBefG [17], vehicles themselves must provide an adequate layout. This means that measures for barrier-free public transport would transfer from stations into busses. 


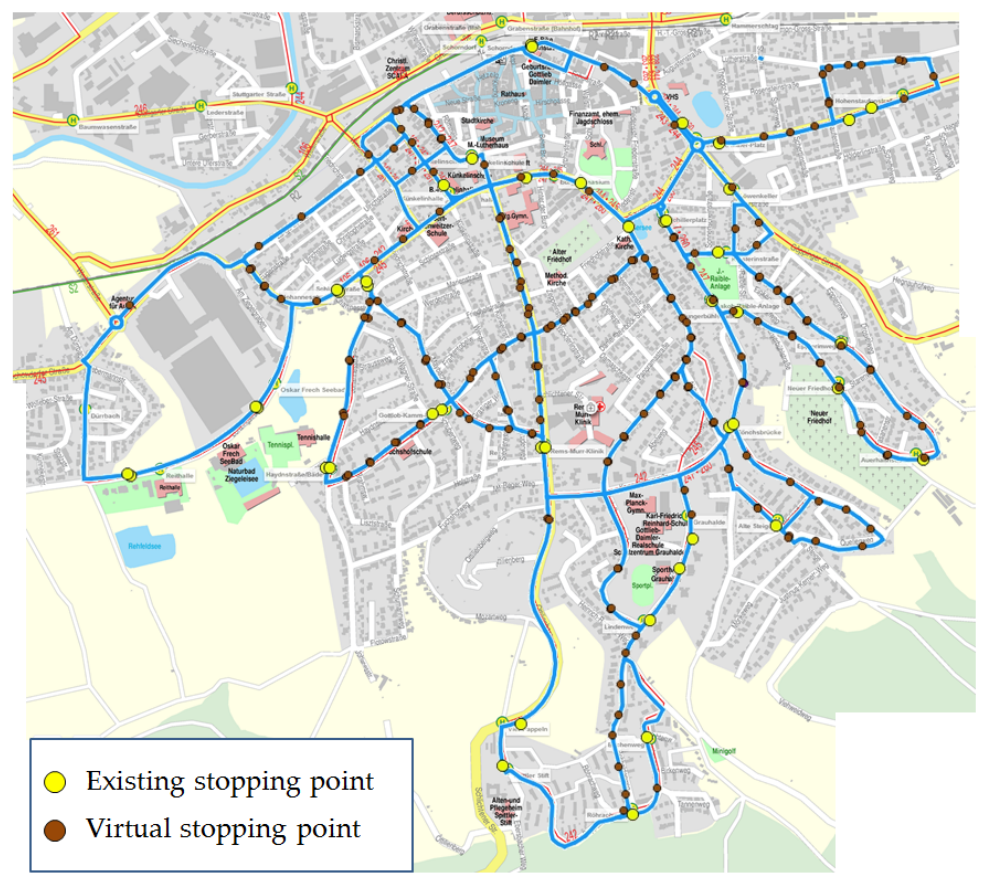

Figure 4. Distribution of planned stopping points.

\subsubsection{Routing: Disposition Algorithm}

Passengers can enter ride requests by four means: smartphone application, telephone service, web interface and local partners such as cafes or public institutions (hospital, swimming pool). Starting point and destination requests might be entered by address, existing stopping point, point of interest or coordinates chosen from an interactive map. The entered starting point and destination might be changed slightly by the system in order to optimize routes. The passenger receives a suggested route with detailed information before booking. Booking may be cancelled by the passengers until the route is fixed: this is valid for all means of booking.

Ride requests collected via smartphone app, web interface, and telephone service will be processed and combined to an optimized route by an algorithm specifically developed for the application in the DRT system in Schorndorf. Optimized route computation is a function of parameters such as the number and spatial distribution of destinations, maximum walking distances for passengers, availability of other transport options (trans-regional bus routes), cycle time, connections to the half-hourly S-Bahn departures/arrivals, and number and type of deployed busses.

Quality and constraints to route optimization are evaluated by simulations. A route factor that represents the ratio of ride time with an on-demand system versus a direct route is computed and can be adjusted for route optimization. Each route is fixed five minutes before a bus starts at Schorndorf main station (starting point of all routes).

Passengers will receive a message to update route information when the route is fixed and will be able to check the status of their trip via smartphone or web interface. Push messages are not considered to be reliable enough to inform passengers. Passengers using the telephone service will receive a fixed departure time when they book their trip. In this case, announced departure time includes a waiting buffer that still allows route disposition according to trip requests received after the telephone booking.

\subsection{Derivation of Vehicle Concept Requirement and Constructive Implementation}

For the pilot phase starting in December 2017, existing vehicles of the Mercedes-Benz Sprinter model range will be used. However, future optimized operation of DRT systems requires vehicle concepts tailored to the system. In the sub-project "vehicle concept", an innovative vehicle concept is developed by scientists from Hochschule Esslingen and DLR together with social scientists and the 
later users. Rising technologies such as automated driving offer new possibilities in vehicle design and will be considered.

Deployment of small and agile vehicles increases the flexibility of demand-oriented systems. However, this would presently result in high operating costs as vehicles are controlled by human drivers. Personnel cost in public transport constitutes a share of approx. 40\% to $70 \%$ ([18,19], depending on boundary conditions). Personnel cost would even increase if many small vehicles were to be used simultaneously. With regard to personal costs and progress in automated driving systems, we assume that the use of autonomous vehicles provides advantages both regarding user requirements (e.g., spacious interior, small vehicles, flexibility of fleet) and economical needs.

Considering today's air quality and noise pollution situation in urban areas, the vehicle concept will possess an environmentally friendly propulsion concept that does not locally emit air pollutants and generates only low noise emission. Reducing noise emission is one of the motivating factors for the project and is a requirement repeatedly expressed by local residents in the operation area. According to the population structure of Schorndorf and the addressed target groups, barrier-free access to the bus and user-centric design are additional central development issues.

As previously described, inter- and transdisciplinary research and development processes represent a central element of real-world laboratories. Accordingly, vehicle design requirements are derived involving a group of Schorndorf's citizens. In a workshop, personas defined in preceding citizen workshops were used to organize citizens, the municipality and scientists (social sciences and engineers) into four groups. Each group discussed vehicle requirements according to specific needs (e.g., design elements for barrier-free access) and developed simple but conclusive hardware prototypes in a 1:10 scale. Various craft materials such as seat or wheelchair patterns and materials allowing for free shape design (e.g., modeling clay, pipe cleaners) were used. An empty Mercedes-Benz Sprinter was available to help workshop participants to gain a feeling for size ratio. The scale 1:10 models showed differences such as importance of appealing interior design and privacy (persona of regular car users) and possibilities to store and secure luggage or walking aids (persona of senior citizens and mobility-restricted persons). The prototype of the persona of regular bus users included a bicycle transport option at the rear of the bus. Barrier-free access was of central importance for all of the four groups, as passengers with small children, buggies or shopping trolleys profit as well as wheelchair users or persons with walking disabilities. Space and securing options for two wheelchairs (instead of one) were elaborated as requirement by the personas of senior citizens and mobility-restricted persons.

Citizen workshop results are complemented by expert interviews and analysis of existing vehicle concepts as well as legislative and normative requirements (e.g., DIN EN 13816:2002-07). Conflicts of objectives are evaluated using the "House of Quality" which is part of the quality function deployment (QFD) method [20-22]. Customer requirements are correlated with functional and technical options in a matrix structure that includes weighting and provides support for conceptual decisions. Relevant issues such as environmental effects, safety, comfort, availability and information provision are addressed.

Development of the vehicle concept is organized in four thematic areas- "complete vehicle", "body", "interior/exterior" and "drive and suspension"—-that will be described in the following.

\subsubsection{Vehicle Concept/Package}

As a combination of the thematic areas mentioned above, the derived concepts and designs were visualized and evaluated by ground planes, 2D-models, sketches and digitally configured conceptual in parameterized CAD models, allowing for efficient variation evaluation. The vehicle design was set up with respect to the predefined requirements and in this connection with different package arrangements. Customer and user requirements as well as technical possibilities within the vehicle package and the operational concept were taken into account [23]. Conditions of the inner-city area of Schorndorf, which serves as an exemplary target operation area, are considered for the definition of vehicle parameters. 
With regard to the above-described conditions and requirements, an autonomous, fully electrically propelled two-axle and low-floor vehicle concept will be developed. The maximum speed is expected to be between 50 and $80 \mathrm{~km} / \mathrm{h}$, adapted to the specific operation purpose of a DRT system with short to medium distances, mainly in inner-city surroundings. A customary inclination of approx. $12 \%$ shall be possible to drive referring to [24], where a maximum of $12 \%$ is recommended for planning certain types of urban streets. The range for the vehicle and the electric energy storage are based on a typical operating day of a bus in Schorndorf and the currently assumed maximum operation duration of three hours (net driving time without recharging in urban surrounding with hilly topology). Drive dimensioning (see Section 2.2.3) and derivation of vehicle dimensions are based on analysis of existing infrastructure (local road system). A vehicle length of at most $5 \mathrm{~m}$ combined with a turning circle of max. $12 \mathrm{~m}$ is presently assumed to meet these requirements best.

\subsubsection{Interior/Exterior}

The vehicle interior is developed in a user-centered, centrifugal way, meaning that the overall vehicle length, width and height result mostly from the physical consideration of the vehicle users by applying the digital man model RAMSIS ${ }^{\mathrm{TM}}$. The model serves for the evaluation of ergonomic aspects. Based on observations of today's usage behavior, four different usage scenarios, which result from vehicle operations at different daytimes, were derived [23] and define the vehicle interior for different types of use. For example, in the case of vehicle operation during main traffic periods, it is assumed that the bus is used by professional commuters, and the interior will be accordingly designed. Another scenario assumes that the bus is used mainly by so-called everyday users and occasional users, which requires different layout features. The four scenarios used for layout derivation are presented in Figure 5.
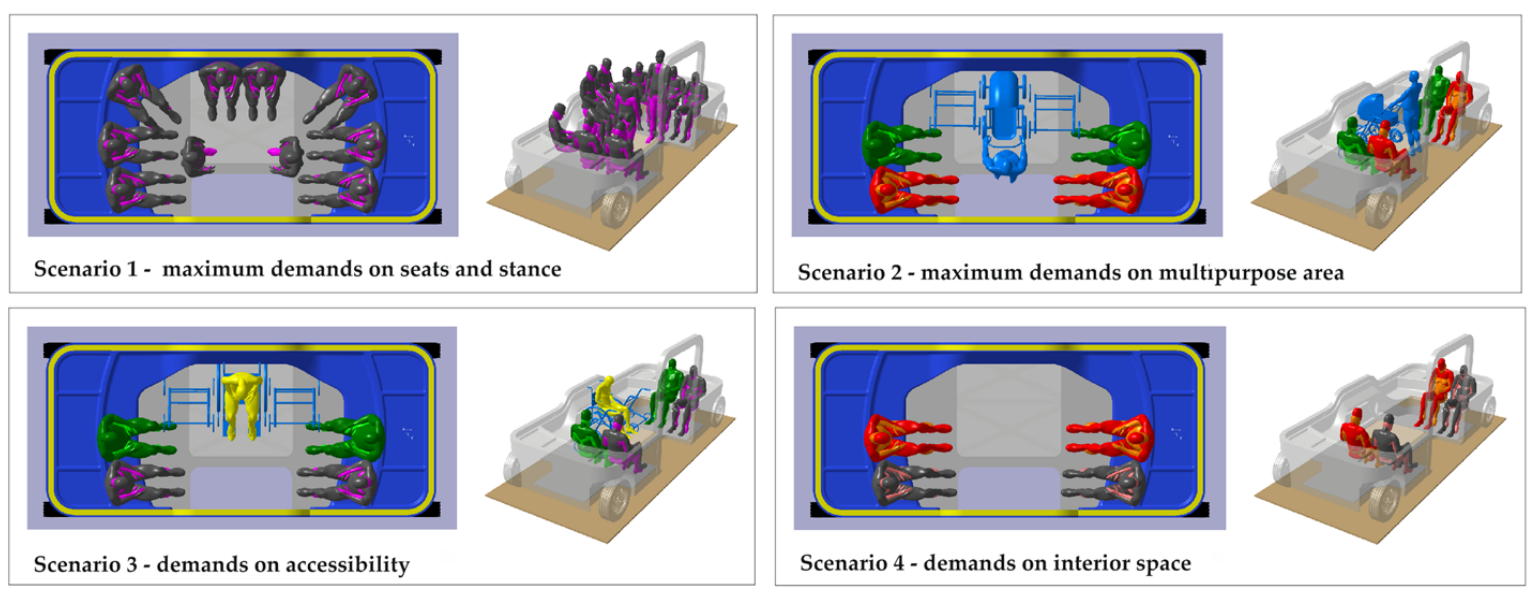

Figure 5. Usage scenarios considered for layout derivation.

Design parameters reflecting the needs of the specific target groups are, for instance, number and position of seats, layout of a multifunctional space (space for luggage, buggies, walking aids, wheelchairs etc.), provision of information or distribution and shape of handholds. The developed design solution takes into account conflicting and common requirements and provides convenient usability for many scenarios.

Since autonomous public transport vehicles are not supported by a bus driver and full accessibility of the vehicle is also required for people with disabilities such as wheelchair users, the requirements relating to the accessibility, operating elements (for passengers) and information systems of the bus are expected to be far higher than in vehicles currently used in public transport. Placing of handholds, equipment with information systems and the interior dimension concept will consider these requirements. 
The vehicle length, width and height take into account the user-centered development of the interior, which is currently developed with six seats and four standing places with small luggage.

\subsubsection{Car Body}

In order to address the requirements in terms of safety, comfort, accessibility, reduction of emissions and energy consumption, a systematic comparison of light-weight potentials was carried out. These potentials include different types of structure, different plastic applications and sandwich structures. In addition to the load-optimized frame structure, the main structural components, e.g., floor, roof and side walls, were designed with different plastic and sandwich configurations and then compared with respect to their lightweight potential. The three pictures in Figure 6 show a simplified version of the three development stages used. At first, a topology optimization using a predefined maximum usable design space and different workloads was made. The result is shown in the first picture of Figure 6. The middle picture is an example of the finite element method (FEM) models used for evaluating the different types of body architecture regarding the results of the topology optimization. The body architectures range from a pure space frame structure to the shown mixed body design with different grades of sandwich structures used. The last of the three illustrations is a conceptual design of the vehicle body without any further work on appearance [25].
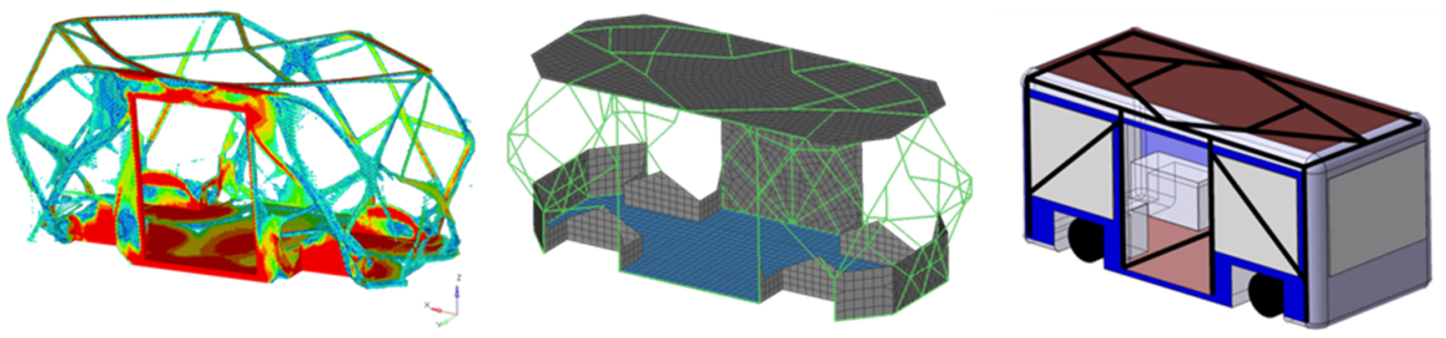

Figure 6. Car body concepts—-topology optimization (left); finite element method (FEM) model (middle); construction concept (right). Reproduced with pression from [25]. Copyright 2017, German Aerospace Center.

According to new design aspects, the first load ideal body frame was adapted. The new space frame body structure consists mostly of straight aluminum profiles with wall thicknesses of 1.0 to $3.5 \mathrm{~mm}$. In order to get the desired floor stiffness, it is designed as a sandwich element. The top layer consists of a 2.5 to $3.0 \mathrm{~mm}$ aluminum sheet, a foam core structure and a lower layer of $1.0 \mathrm{~mm}$ sheet, where the foam parameters as well as the ideal layer thicknesses are still under investigation. For the chassis mounting, $10 \mathrm{~mm}$ aluminum sheet metal housings are welded together as a first concept. As an optimization potential, the housings can be made of aluminum castings, which still has to be evaluated. The roof frame is made of bent tubes with a diameter of $100 \mathrm{~mm}$ and a thickness of $1 \mathrm{~mm}$. The roof itself is designed with a $1 \mathrm{~mm}$ aluminum sheet.

\subsubsection{Power Unit/Chassis}

Due to a purely electric drive, the noise emissions are reduced significantly and air pollution, especially in the inner-city area, is avoided.

In order to define the drivetrain design, the inner-city bus lines of Schorndorf were tracked with a GPS data logger (cp. Figure 7). On the basis of the captured data, an analytical consumption estimation [26] was carried out with the software application Matlab. Route lengths of considered bus routes in Schorndorf are around $10 \mathrm{~km}$. As a result of logging data analysis, four permanent magnet synchronous gearless in-wheel motors are selected by considering the necessary torque $(460 \mathrm{Nm})$ and rotation speed (606 RPM) resulting from top-speed rides on the flat of $80 \mathrm{~km} / \mathrm{h}$ and the necessary torque for hill-starting on a road gradient of $12 \%$ at full payload $(2666 \mathrm{Nm})$ [23]. Battery pack parameters are accordingly defined and provide energy for a net driving time of three hours in urban surrounding 
and hilly topology ( $58 \mathrm{kWh}$ for $3 \mathrm{~h}$ ). Therefore, two $400 \mathrm{~V}$-battery packs with nominal capacity of $72.5 \mathrm{Ah}$ each, one per axle, mass per energy of $10.4 \mathrm{~kg} / \mathrm{kWh}$, and volume per energy of $6.6 \mathrm{~L} / \mathrm{kWh}$ are used.
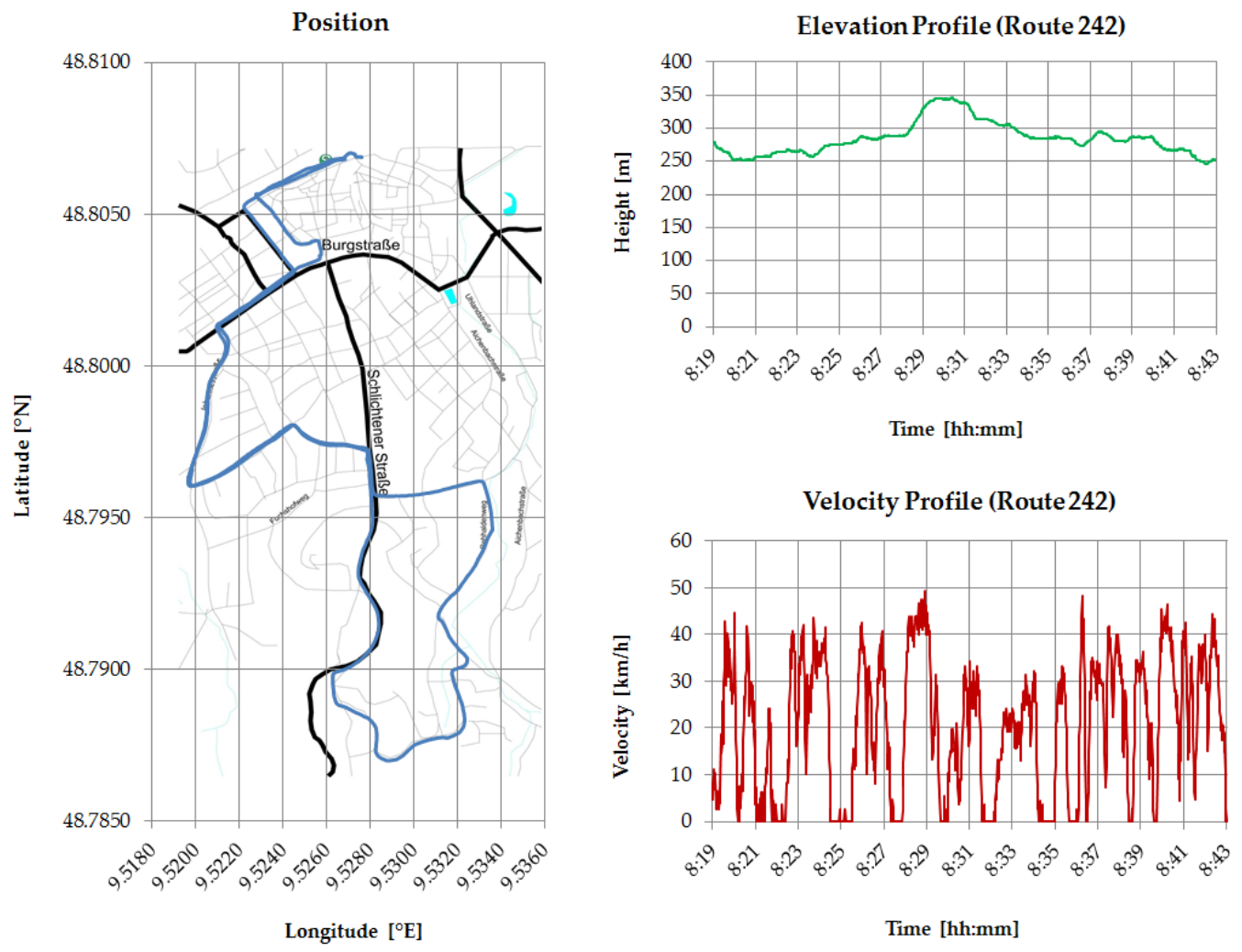

Figure 7. GPS-tracked inner-city bus lines of Schorndorf-route alignment (left) elevation (upper right) and velocity profile (lower right).

\section{Conclusions and Outlook}

Within the first phases of the BOOLEAN project, local situation and boundary conditions in the municipality of Schorndorf were analyzed. System requirements were derived in an inter- and transdisciplinary process incorporating needs and knowledge from local citizens, the municipality, a transportation company, a bus operating company and a vehicle manufacturer. Results from the participative process and constraints such as number of deployable busses, operable area size, and the integration of certain points of interest led to the decision to define the southern part of the urban core of Schorndorf as the operating area. Discrete stopping points were defined in this area instead of continuous pick-up areas in order to offer more efficient routes, simplified passenger identification and deal with local stopping restrictions. Translation of operation system requirements into technical parameters was accomplished, and implementation in the form of the routing algorithm and smartphone application was largely completed.

Complementing the DRT system development, virtual vehicle concepts were developed, as the future optimized operation of DRT systems requires vehicle concepts tailored to the system. Equivalent to the development of the DRT system, participative methods were used for vehicle concept parameter derivation. Accordingly, an autonomous, fully electrically propelled two-axle and low-floor vehicle concept is being developed. The maximum speed is expected to be between 50 and $80 \mathrm{~km} / \mathrm{h}$, adapted to the specific operation purpose of an on-demand system with short to medium distances, mainly in inner-city surroundings. Propulsion is realized by four permanent magnet synchronous gearless in-wheel motors providing a torque of $460 \mathrm{Nm}$ and rotation speed of $606 \mathrm{RPM}$. The capacity of the electric energy storage is $58 \mathrm{kWh}$, based on a typical operating day of a bus in Schorndorf and the 
currently assumed maximum operation duration of three hours (net driving time without recharging in urban surrounding with hilly topology). The interior layout design prioritizes requirements regarding accessibility, ergonomics of operating elements (for passengers) and information systems of the bus, taking into account the fact that autonomous vehicles must provide convenient design for self-reliant use to all kind of passengers.

The car body supporting the interior design was developed using topology optimization, FEM simulations and considering attractive vehicle exterior design. The new space frame body structure consists mostly of straight aluminum profiles. In order to get the desired floor stiffness, it is designed as a sandwich element.

Testing of the smartphone application will be accomplished within 2017. In March 2018, the pilot phase of the DRT system will start. In the southern part of the urban core of Schorndorf, an on-demand service will be offered which can be booked by smartphone application, web interface or telephone service. The evaluation concept is presently being elaborated in detail and will comprise collection and analysis of logged data and interviews.

Author Contributions: Conceptualization, M.B. and M.K.; Methodology, M.B., E.-M.F., S.B., G.K. and A.M.; Software, K.K.; Validation, K.K.; Formal Analysis, K.K.; Investigation, M.B., M.K., G.K., O.D., E.-M.F., K.K., T.S., A.M. and S.B.; Writing-Original Draft Preparation, M.B., K.K., G.K., A.M. and S.B.; Writing-Review \& Editing, M.B., G.K., O.D., K.K., A.M. and S.B.; Visualization, M.B., G.K., O.D., K.K., A.M. and S.B.; Supervision, M.K.; Project Administration, M.K.; Funding Acquisition, M.K.

Acknowledgments: The project “Bürgerorientierte Optimierung der Leistungsfähigkeit, Effizienz und Attraktivität im Nahverkehr (BOOLEAN)" is one of the real-world laboratories funded by the state of Baden-Württemberg by the Ministry of Science, Research and the Arts. Vehicles deployed within the project duration are kindly provided by Mercedes-Benz Vans (Daimler AG) and Hochschule Esslingen.

Conflicts of Interest: The authors declare no conflicts of interest.

\section{References}

1. Door2Door GmbH. Allygatorshuttle. Available online: https://www.allygatorshuttle.com/en/index.html (accessed on 18 May 2018).

2. Wang, C.; Quddus, M.; Enoch, M.; Ryley, T.; Davison, L. Exploring the propensity to travel by demand responsive transport in the rural area of Lincolnshire in England. Case Stud. Transp. Policy 2015, 3, 129-136. [CrossRef]

3. ASEAG_-Aachener Straßenbahn und Energieversorgungs-AG, "NetLiner für Monschau”. Available online: https: / / www.aseag.de/fahrplan/netliner-fuer-monschau/ (accessed on 18 May 2018).

4. Enoch, M.; Potter, S.; Parkhurst, G.; Smith, M. Why do Demand Responsive Transport Systems fail? In Proceedings of the 85th Annual Meeting of the TRB, Washington, DC, USA, 22-26 January 2006.

5. Winkelmann, U. Die Pendlermobilität Steigt Überall in Baden-Württemberg; Statistisches Monatsheft: Stuttgart, Germany, 2012; pp. 25-28.

6. HWWI (Hamburgisches Welt Wirtschafts Institut). Pendeln in Hamburg. Policy Paper. Available online: http:/ / www.hwwi.org/uploads/tx_wilpubdb/HWWI-Policy_Paper_83.pdf (accessed on 23 June 2015).

7. Via Transportation, Inc. Welcome to via. We Ride Together. Available online: https://ridewithvia.com/ (accessed on 18 May 2018).

8. Brandies, A.; König, A.; Viergutz, K.; Fraedrich, E.-M.; Gebhardt, L.; Ulmer, F.; Sippel, T.; Dotzauer, M. Transdisziplinäre Mobilitätsforschung unter Verwendung von Reallaboren: Integration von Stakeholderbedürfnissen und -anforderungen in die Entwicklung von Sys-Temen Bedarfsorientiert und Vollautomatisiert Fahrender Quartiersbusse. In Proceedings of the AEET 2017 Automatisiertes und Vernetztes Fahren, Braunschweig, Deutschland, 8-9 February 2017.

9. Holm, P.; Goodsite, M.; Cloethingh, S.; Agnoletti, M.; Moldan, B.; Lang, D.J.; Leemans, R.; Moeller, J.O.; Buendia, M.P.; Pohl, W.; et al. Collaboration between the natural, social and human sciences in globale change research. Environ. Sci. Policy 2012, 28, 25-35. [CrossRef]

10. Schneidewind, U. Urbane Reallabore: Ein Blick in Die Aktuelle Forschungswerkstatt in Pnd I Online. Available online: https://epub.wupperinst.org/frontdoor/deliver/index/docId/5706/file/5706_ Schneidewind.pdf (accessed on 23 June 2015). 
11. Brown, T. Design Thinking. Harv. Bus. Rev. 2008, 86, 84-92. [PubMed]

12. Mayas, C.; Hörold, S.; Krömker, H. Meeting the Challenges of Individual Passenger Information with Personas. In Advances in Human Aspects of Road and Rail Transportation; CRC Press: Boca Raton, FL, USA, 2012; pp. 822-831.

13. Zave, P. Classification of Research Efforts in Requirements Engineering. ACM Comput. Surv. 1997, 29, 315-321. [CrossRef]

14. König, A.; Brandies, A.; Schnieder, L.; Dotzauer, M.; Jipp, M. Zukunftsszenarien autonomer Fahrzeuge-Nutzungsorientierte Gestaltung eines individuell abrufbaren Personentransportsystems. In Proceedings of the 5 Interdisziplinärer Workshop Kognitive Systeme, Bochum, Germany, 14-16 March 2016; Volume 5.

15. Sippel, T.; Ulmer, F.; Alcantara, S.; Klötzke, M.; Fraedrich, E.-M.; Gebhardt, L. When citizens become experts. A new approach for an integrated project and participation management. In Proceedings of the IST 2017, Gothenburg, Sweden, 18-21 June 2017.

16. Niebel, W.; Sauerländer-Biebl, A. Challenges in static data acquisition for a bus-on-demand line. In Proceedings of the Workshop on Smart Mobility, Luxembourg, 1-2 June 2017.

17. Personenbeförderungsgesetz (PBefG); German Federal Government: Berlin, Germany, 2013.

18. Sax, E. Wirtschaftlichkeit des elektrifizierten Busbetriebs. [Power Point Presentation]. In Proceedings of the 8 ÖPNV Innovationskongress, Freiburg, Germany, 14-16 March 2017.

19. Frank, P.; Friedrich, M.; Schlaich, J. Betriebskosten von Busverkehren Schnell und Genau Ermitteln; Der Nahverkehr, Alba Fachverlag: Düsseldorf, Germany, 2008; pp. 15-22.

20. Bors, M. Ergänzung der Konstruktionsmethodik um Quality Function Deployment-Ein Beitrag zum Qualitätsorientierten Konstruieren; Carl Hanser Verlag: München, Germany, 1994.

21. Schaaf, A. Marktorientiertes Entwicklungsmanagement in der Automobilindustrie-Ein Kundennutzenorientierter Ansatz zur Steuerung des Entwicklungsprozesses; Deutscher Universitäts-Verlag: Wiesbaden, Germany, 1999.

22. Wildemann, H. Kundenorientierte Produktentwicklung in der Automobilindustrie. In Nachhaltiges Innovationsmanagement; Springer Fachmedien: Wiesbaden, Germany, 2004.

23. Müller, A.; Kopp, G.; Beyer, S.; Deisser, O. Reallabor Schorndorf-Bedarfsgerecht und Nutzerorientiert, Spektrum, Zeitschrift der Hochschule Esslingen 44/2017. Available online: http:/ / www.hs-esslingen.de/ index.php?id=95154 (accessed on 12 May 2017).

24. Richtlinien für die Anlage von Stadtstraßen; Forschungsgesellschaft für Strassen- und Verkehrswesen (FGSV): Köln, Germany, 2008.

25. Kopp, G.; Müller, A.; Deißer, O.; Beyer, S. Innovative Kunststoffanwendungen für ein Kleines Stadtbuskonzept; VDI Verlag GmbH: Düsseldorf, Germany, 2017.

26. Zirn, O. Elektrifizierung in der Fahrzeugtechnik: Grundlagen und Anwendungen; Fachbuchverlag Leipzig im Carl Hanser Verlag: München, Germany, 2017. 